\title{
US biomedical RED spending declines, Asian spending soars
}

Shifts in industry, rather than public, investments are driving changes in the regional biomedical RED landscape.

The lowdown: Justin Chakma, a venture capital investor at Thomas, McNerney \& Partners in La Jolla, California, and his colleagues obtained data on biomedical research and development (RED) expenditure in the United States, Europe and Asia-Oceania to look at spending trends between 2007 and 2012 (N. Engl.J. Med. 370, 3-6; 2014). While inflation-adjusted expenditure was stable over 5 years, increasing by only US $\$ 6.3$ billion (2.4\%) to $\$ 268$ billion in 2012 , the regional balance of biomedical research funding is changing (see figure).

Biomedical spending in the United States accounted for only $45.4 \%$ of the global RED spend in 2012, when adjusted for purchasing-power parity, down from $51.2 \% 5$ years prior, they report. "The decline is remarkable because the United States has provided a majority of the funding for biomedical RED globally for the past two decades - a share that some previous analyses suggested was as high as 70 to $80 \%$," the authors write. Overall, the compound annual growth rate of biomedical spending from 2007 to 2012 in the United States was $-1.9 \%$. Other regions that experienced a fall in compound annual growth rates were Europe, of $-0.4 \%$, and Canada, of $-2.6 \%$.

These losses were mirrored by gains in Asia-Oceania, especially in China and South Korea. The compound annual growth rate from 2007 to 2012 was $32.8 \%$ in China, and was $11.4 \%$ in South Korea.

The authors also broke funding down by source, comparing levels of public and private funding. The decline of funding in the United States was driven primarily by a $\$ 13$ billion inflation-adjusted reduction in industry's investment there, they report, to $\$ 70$ billion in 2012. Public funding in the United States during this time was stable, at $\$ 48-49$ billion. Industry investment in China, by contrast, grew by $\$ 4.8$ billion, reaching $\$ 6.3$ billion in 2012 . Public spending in China also grew, by $\$ 1.4$ billion, to $\$ 2$ billion.

"One explanation for the shift in global RED expenditures may be the attractive cost of conducting R\&D in Asia-Oceania, where labor is cheaper and greater government subsidies are available," the authors write. "Accordingly, we found that the US share declined even as global R\&D investments by industry remained flat (after adjustment for inflation), which suggests that industry is simply reallocating RED funding to Asia-Oceania." National Institutes of Health (NIH) funding alone is unlikely to be a sustainable way of retaining long-term RED leadership in the United States, they add, and the US government also needs new incentives to induce industry to invest if it wants to stay competitive.
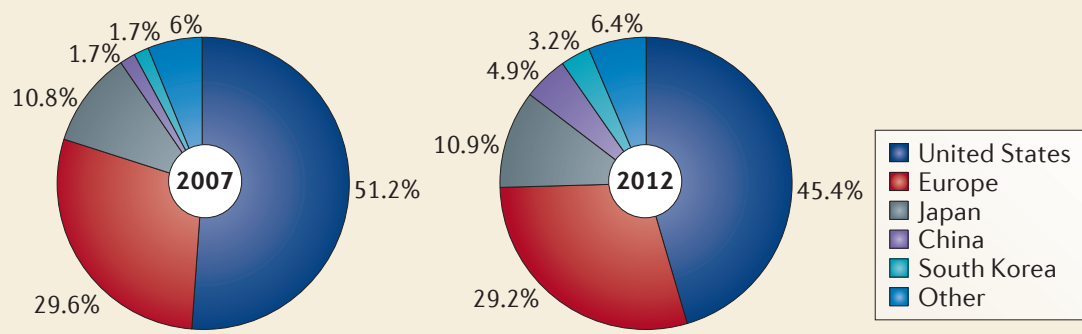

Regional breakdown of biomedical R\&D spending, adjusted for purchasing-power parity.

\section{A step closer to European clinical trial reform}

European parliament reaches provisional agreement on new rules for clinical trial authorization procedures.

The lowdown: The European Clinical Trials Directive was introduced in 2001 to harmonize clinical trial authorization procedures across Europe, but it failed miserably and is thought to have contributed to a decline in the number of trials carried out in Europe (trials fell by $25 \%$ from 2007 to 2011, according to one analysis). In a bid to fix an overly bureaucratic and slow process, the European Commission unveiled a new regulation in July 2012 to streamline clinical trial authorization (Nature Rev. Drug Discov. 11.660-661; 2012). After a year and a half of negotiations with stakeholders, the European Union's Permanent Representatives Committee has approved a compromise agreement.
The regulation smoothes the trial application process such that sponsors will submit their trial requests through a single portal. A single authorization procedure will also be put in place across all EU member states. Under the terms of the compromise, trial applications for standard therapies must be reviewed within 60 days, and applications for complex medicinal products must be reviewed within 110 days. These are up from original proposed review deadlines of 48-79 days. Companies will also have to submit the results of all European studies to a publicly accessible database, a move brought on by calls for greater transparency in drug development.

The agreement now needs to be authorized by the Council of Ministers and the European Parliament plenary, and could be finalized before May.

\section{Lead GPR40 agonist bites the dust}

Takeda discontinued the Phase III candidate fasiglifam because of liver toxicity, dealing another blow to a beleaguered class of potential antidiabetic drugs.

The lowdown: Takeda opened GPR40 up as a possible antidiabetic drug target in 2003, when its researchers reported that long-chain free fatty acids are ligands for the once-orphan $\mathrm{G}$ protein-coupled receptor and modulate insulin secretion (Nature 422, 173-176; 2003). While several companies jumped on this development lead, Takeda was ahead of the pack with its GPR40 agonist fasiglifam. The company advanced the drug into Phase III trials in 2011 and looked on track for a first-in-class approval.

But Takeda's lead - along with its hopes for a near-term successor to the antidiabetic blockbuster pioglitazone (Actos) - were dashed in December when it discontinued development of fasiglifam. The decision was driven by "concerns about liver safety", the company said in a statement. Takeda did not disclose whether it thought the liver toxicity signal was candidate- or mechanism-specific.

Astellas Pharma discontinued its Phase I GPR40 agonist ASP5034 in 2012 "after comprehensive review of [Phase I] study results and the competitive situation". Lilly and Amgen have also discontinued clinical development of their respective LY2881835 and AMG837, for undisclosed reasons. Japan Tobacco's JTT-851 is still in Phase II trials. Bristol-Myers Squibb, Merck \& Co. and Amgen reportedly have preclinical GPR 40 programmes. 